\title{
The Role of Iron in Ti on the Growth of Ti Silicides in Bulk Ti/Si Diffusion Couples
}

\author{
Toshitada Shimozaki*, Takahisa Okino**, Masahiro Yamane*** \\ and Chan-Gyu Lee****
}

\author{
${ }^{*}$ The Center for Instrumental Analysis, Kyushu Institute of Technology, Kitakyushu 804-8550, Japan \\ ${ }^{* *}$ College of Liberal Arts and Sciences, Nippon Bunri University, Oita 870-0316, Japan \\ ${ }^{* * *}$ Department of Materials Science and Engineering, Kyushu Institute of Technology, \\ Kitakyushu 804-8550, Japan \\ ****Department of Materials Science and Engineering, Changwon National University, \\ Changwon, Kyungnam 541-773, Korea
}

\begin{abstract}
Reaction diffusion in the Ti-Si system has been studied to clarify the roll of iron in $\mathrm{Ti}$ on the growth of $\mathrm{TiSi}_{2}$ by using sandwich type diffusion couples consisting of $99.5 \%(2 \mathrm{~N}) \mathrm{Ti}, 99.9999 \%(6 \mathrm{~N}) \mathrm{Ti}$ and $\langle 111\rangle$ oriented $\mathrm{Si}$ wafer in the temperature range between 1164 and $1323 \mathrm{~K}$. The growth of $\mathrm{TiSi}_{2}$ formed in $2 \mathrm{~N}-\mathrm{Ti} / \mathrm{Si}$ diffusion couples at the lowest temperature in this experiment, $1164 \mathrm{~K}$, was slower than that in a $6 \mathrm{~N}-\mathrm{Ti} / \mathrm{Si}$ couples. The difference between the growth rate of $2 \mathrm{~N}-\mathrm{Ti} / \mathrm{Si}$ and that in $6 \mathrm{~N}-\mathrm{Ti} / \mathrm{Si}$ diffusion couples becomes to be small and to have the same value at $1213 \mathrm{~K}$. These results could be expected from our previous experimental results that the higher the purity of Ti the faster the growth rate and that the lower the purity of Ti the larger the activation energy in the temperature range between 973 and 1123 $\mathrm{K}$. However, the Arrhenius plot of the growth rate, $k^{2}$, for $2 \mathrm{~N}-\mathrm{Ti} / \mathrm{Si}$ couple bends at $1213 \mathrm{~K}$ and have the same value as the $6 \mathrm{~N}-\mathrm{Ti} / \mathrm{Si}$ diffusion couples above $1213 \mathrm{~K}$.

As a possible explanation for this behavior of the growth of $\mathrm{TiSi}_{2}$ in the $2 \mathrm{~N}-\mathrm{Ti} / \mathrm{Si}$ couple it has been considered that in the high temperature range impurity iron atoms which segregate at grain boundaries of $\mathrm{TiSi}_{2}$ and slow down the movement of titanium and silicon atoms diffusing through the grain boundaries in the lower temperature range will redistribute into matrix and the effects become negligible small at high temperature.
\end{abstract}

(Received March 12, 1999)

Keywords: titanium-silicon system, reaction diffusion, titanium silicide, titanium disilicide, high purity titanium, boundary diffusion, impurity

\section{Introduction}

In the field of device technology, titanium silicides have attracted attention because of their low and metallike resistivity and their high temperature stability. So the interaction between thin film titanium and silicon wafer has been studied in the past ${ }^{(1)-(5)}$. However, very little is known about the formation and growth kinetics of titanium silicides. The authors have previously ${ }^{(6)(7)}$ studied the reactive diffusion in the Ti-Si binary system by using bulk diffusion couples consisting of $99.5 \% \mathrm{Ti}(2 \mathrm{~N}-$ $\mathrm{Ti}), 99.99 \% \mathrm{Ti}(4 \mathrm{~N}-\mathrm{Ti})$ and $99.9999 \% \mathrm{Ti}(6 \mathrm{~N}-\mathrm{Ti})$ and a silicon wafer having $\langle 111\rangle$ orientation. The results have been summarized in Fig. 1 (see Fig. 5 in Ref. (7)) where the Arrhenius plots of growth rates $k^{2}$ of $\mathrm{TiSi}_{2}$ formed in various kinds of diffusion couples are shown. Figure 1 shows that the growth of $\mathrm{TiSi}_{2}$ is faster the higher the purity of Ti. To identify the element which slows down the growth rate of $\mathrm{TiSi}_{2}$ in bulk $\mathrm{Ti} / \mathrm{Si}$ diffusion couples, the effect of irons, nitrogen, oxygen and carbon was studied by depositing iron or carbon on $6 \mathrm{~N}$ - Ti plates in an evacuated chamber at room temperature and absorbing oxygen or nitrogen gas into the $6 \mathrm{~N}-\mathrm{Ti}$ plates in a quartz capsule at $1073 \mathrm{~K}$. Ti specimens thus made were called as $\mathrm{Ti}(\mathrm{Fe})$ or $\mathrm{Ti}(\mathrm{O})$ and so on. Sandwich-type diffusion couples, consisting of these $\mathrm{Ti}$ specimens and silicon wafer, for example, $\mathrm{Ti}(\mathrm{Fe}) / \mathrm{Si} / 6 \mathrm{~N}-\mathrm{Ti}$, were made. As shown in Fig. 1, the growth rate of $\mathrm{TiSi}_{2}$ formed in $\mathrm{Ti}(\mathrm{Fe}) / \mathrm{Si}$ diffusion couples is controlled while those in $\mathrm{Ti}(\mathrm{N}) / \mathrm{Si}$ and $\mathrm{Ti}(\mathrm{O}) / \mathrm{Si}$ are not. Since it has also been clarified that iron atoms segregate at the grain boundary of $\mathrm{TiSi}_{2}$ in the lower temperature range ${ }^{(7)}$, the authors concluded that iron atoms which segregate at the boundary slow down the diffusion of $\mathrm{Ti}$ and $\mathrm{Si}$ which pass through the boundary. Consequently, grain boundary diffusion has been suggested as a dominant process for the growth of the $\mathrm{TiSi}_{2}$ in the $\mathrm{Ti} / \mathrm{Si}$ diffusion couples.

From the Fig. 1, it is expected that the growth of $\mathrm{TiSi}_{2}$ for $2 \mathrm{~N}-\mathrm{Ti} / \mathrm{Si}$ diffusion couples becomes faster than that for $6 \mathrm{~N}-\mathrm{Ti} / \mathrm{Si}$ couples in the high temperature range because the activation energy for $2 \mathrm{~N}-\mathrm{Ti} / \mathrm{Si}$ diffusion couples is larger than that for $6 \mathrm{~N}-\mathrm{Ti} / \mathrm{Si}$ couples. However, according to our previous results ${ }^{(7)}$ it has been suggested that the growth rate of $\mathrm{TiSi}_{2}$ in a $2 \mathrm{~N}-\mathrm{Ti} / \mathrm{Si}$ couple cannot be faster than that in $6 \mathrm{~N}-\mathrm{Ti} / \mathrm{Si}$ couple because iron in a $2 \mathrm{~N}-\mathrm{Ti}$ slows down the growth of $\mathrm{TiSi}_{2}$ in the $2 \mathrm{~N}-\mathrm{Ti} / \mathrm{Si}$ couple $^{(7)}$.

This experiment has been performed to check this point of view. By this experimental results the roll of iron is expected to be clear. Ti transforms from the hcp to the bcc structure at $1156 \mathrm{~K}$, so the effect of change in crystal 


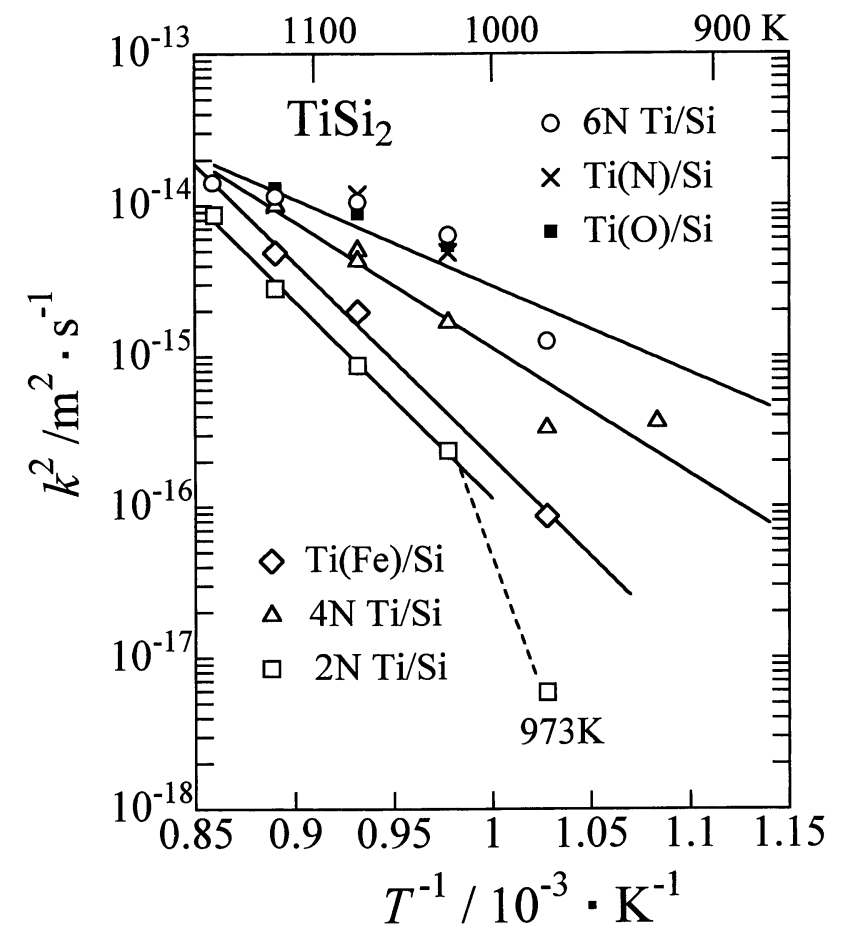

Fig. 1 Temperature dependence of the growth rates $k^{2}$ of $\mathrm{TiSi}_{2}$ for various kinds of diffusion couples.

structure on the growth behavior of titanium silicides is also studied.

Silicides combine excellent oxidation resistance, a high melting point and reasonable strength and density, making them a promising material for structural applications at high temperature. For such applications, data on diffusion in bulk samples are indispensable.

\section{Experimental Procedure}

A 6N titanium disk (Sumitomo SiTiX Co. LTD) and a $2 \mathrm{~N}$ titanium sheet used here are the same one as those in the previous paper ${ }^{(6)(7)}$. The concentration of $\mathrm{Fe}$ was 200 ppm for $2 \mathrm{~N}-\mathrm{Ti}$ and less than $0.1 \mathrm{ppm}$ for $6 \mathrm{~N}-\mathrm{Ti}$, respectively. They were rolled and cut to the specimens about 10 $\mathrm{mm} \times 10 \mathrm{~mm} \times 0.5 \sim 1.5 \mathrm{~mm}$ in size. The thick specimens were used for the experiment at high temperature for a long period of anneal. Ti specimens thus made were not recrystallized to avoid the contamination during the anneal. As it has been shown ${ }^{(6)}$, any differences between the growth of silicides formed in a recrystallized $\mathrm{Ti} / \mathrm{Si}$ couple and a non-recrystallized $\mathrm{Ti} / \mathrm{Si}$ diffusion couple have not been found. A $\langle 111\rangle$ oriented, $12.4 \mathrm{~mm}$ diameter, $0.6 \mathrm{~mm}$ thickness silicon wafer was cut to the same size of Ti specimen. The contact surfaces of $\mathrm{Si}$ and $\mathrm{Ti}$ specimens were ground on abrasive papers and polished metallographically on a buff with fine alumina powder. The surface of $\mathrm{Ti}$ is chemically polished in a solution consisting of $30 \% \mathrm{HF}$ and $70 \%$ fuming $\mathrm{HNO}_{3}$.

The Ti specimen thus prepared was tightened together with a Si specimen by a stainless steel clamp. To perform the experiment under the same conditions, $6 \mathrm{~N}$ -
$\mathrm{Ti} / \mathrm{Si} / 2 \mathrm{~N}-\mathrm{Ti}$ sandwich-type diffusion couples were assembled. The couple was heated in an evacuated furnace at a pressure of about $10^{-5} \mathrm{~Pa}$ at $1164,1213,1266,1292$ and $1323 \mathrm{~K}$ for various periods of heating time. After the heating they were removed and mounted in a resin. The cross section of the diffusion zone was polished metallographically and analyzed by an electron probe micro analyzer (EPMA: JEOL JCXA 733).

\section{Results}

\section{Ti silicides formed in $2 \mathrm{~N}-\mathrm{Ti} / \mathrm{Si}$ and $6 \mathrm{~N}-\mathrm{Ti} / \mathrm{Si}$ diffusion couples}

In the Ti-Si binary phase diagram ${ }^{(8)}$, five kinds of silicides, i.e., $\mathrm{Ti}_{3} \mathrm{Si}, \mathrm{Ti}_{5} \mathrm{Si}_{3}, \mathrm{Ti}_{5} \mathrm{Si}_{4}$, TiSi and $\mathrm{TiSi}_{2}$, are represented. Four kinds of the silicides have already been detected in both $\mathrm{Ti} / \mathrm{Si}$ diffusion couples ${ }^{(6)(7)}$. Two of them from $\mathrm{Si}$ side are $\mathrm{TiSi}_{2}$ and $\mathrm{TiSi}$ respectively. The rest two layers were too narrow to be identified. At the highest temperature in this experiment, 5 kinds of silicides could be found by the EPMA component image. The concentrations of these silicides determined by the ZAF method are shown in Table 1. That for the third layer from $\mathrm{Si}$ side corresponds to $\mathrm{Ti}_{5} \mathrm{Si}_{4}$. The rest two layers can be supposed to be $\mathrm{Ti}_{5} \mathrm{Si}_{3}$ and $\mathrm{Ti}_{3} \mathrm{Si}$, respectively.

\section{Growth behavior of titanium silicides}

The relationships between the widths, $W$, of $\mathrm{TiSi}_{2}$ and TiSi formed in $6 \mathrm{~N}-\mathrm{Ti} / \mathrm{Si}$ and $2 \mathrm{~N}-\mathrm{Ti} / \mathrm{Si}$ diffusion couples and the square root of annealing time, $t$, at 1164, 1266, 1292 and $1323 \mathrm{~K}$ are shown in Fig. 2 through Fig. 5. At $1164 \mathrm{~K}$, both $\mathrm{TiSi}_{2}$ and TiSi grow satisfying the parabolic law. The widths of $\mathrm{TiSi}_{2}$ and TiSi formed in $6 \mathrm{~N}-\mathrm{Ti} / \mathrm{Si}$ diffusion couple are obviously thicker than that in $2 \mathrm{~N}$ $\mathrm{Ti} / \mathrm{Si}$ couples. On the other hand, the total width and the width of TiSi formed in these diffusion couples at 1266, 1292 and $1323 \mathrm{~K}$ are almost the same. It should be noted, here, that the growth of TiSi in $2 \mathrm{~N}-\mathrm{Ti} / \mathrm{Si}$ diffusion couple at $1266 \mathrm{~K}$ satisfy the parabolic law, while the growth of $\mathrm{TiSi}_{2}$ does not. Similar growth of $\mathrm{TiSi}$ and $\mathrm{TiSi}_{2}$ was also found at $1292 \mathrm{~K}$ at shown in Fig. 4. At these temperature the growth of $\mathrm{TiSi}_{2}$ at the early stage of the anneal is rapid and the width in $2 \mathrm{~N}-\mathrm{Ti} / \mathrm{Si}$ couple is thicker than the $6 \mathrm{~N}-\mathrm{Ti} / \mathrm{Si}$ couple though it becomes slow and the width is reversed. So at 1266 and $1292 \mathrm{~K}$, two values of $k^{2}$ for $\mathrm{TiSi}_{2}$ have been determined. One is determined by the

Table 1 Concentrations of silicides determined by the ZAF method.

\begin{tabular}{cccl}
\hline \hline \multirow{2}{*}{$\begin{array}{c}\text { Layer number } \\
\text { from Si side }\end{array}$} & \multicolumn{2}{c}{$\mathrm{Ti}(\mathrm{at} \%)$} & \multirow{2}{*}{ Phase } \\
\cline { 2 - 3 } & $\mathrm{ZAF}$ & Stoichiometry & \\
\hline 1 & 33.4 & 33.33 & $\mathrm{TiSi}_{2}$ \\
2 & 50.1 & 50.0 & $\mathrm{TiSi}$ \\
3 & 55.1 & 55.56 & $\mathrm{Ti}_{5} \mathrm{Si}_{4}$ \\
4 & 60.9 & 62.5 & $\mathrm{Ti}_{5} \mathrm{Si}_{3} ?$ \\
5 & - & - & $\mathrm{Ti}_{3} \mathrm{Si}^{2}$ \\
\hline \hline
\end{tabular}




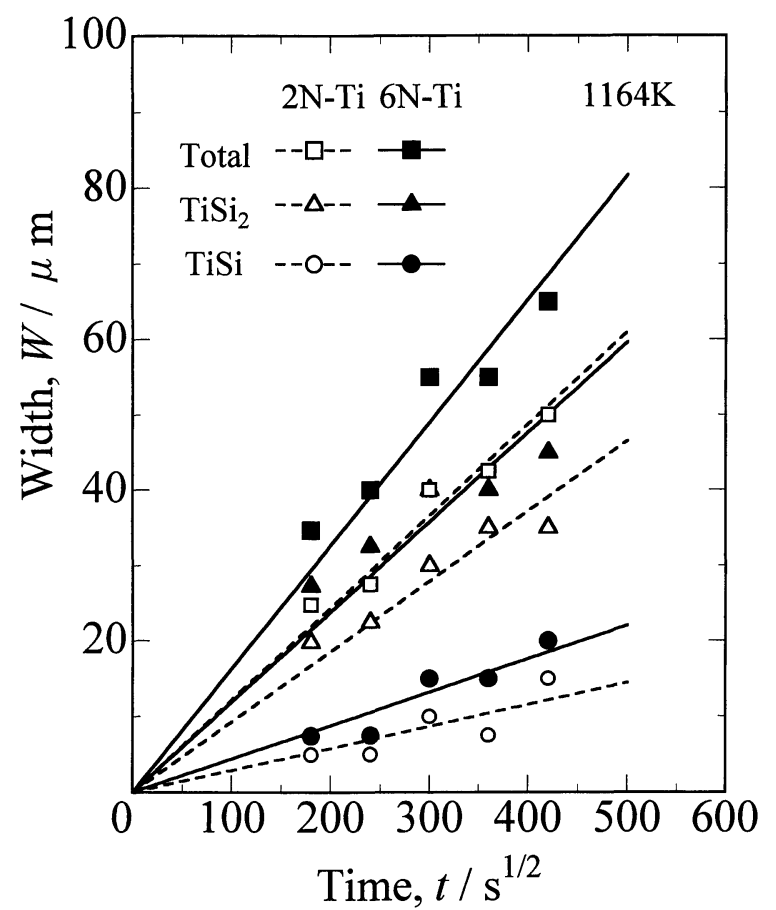

Fig. 2 Relationship between thickness, $W$, of $\mathrm{TiSi}_{2}$ and TiSi layers formed in the $2 \mathrm{~N}-\mathrm{Ti} / \mathrm{Si}$ and $6 \mathrm{~N}-\mathrm{Ti} / \mathrm{Si}$ diffusion couples and square root of annealing time at $1164 \mathrm{~K}$.

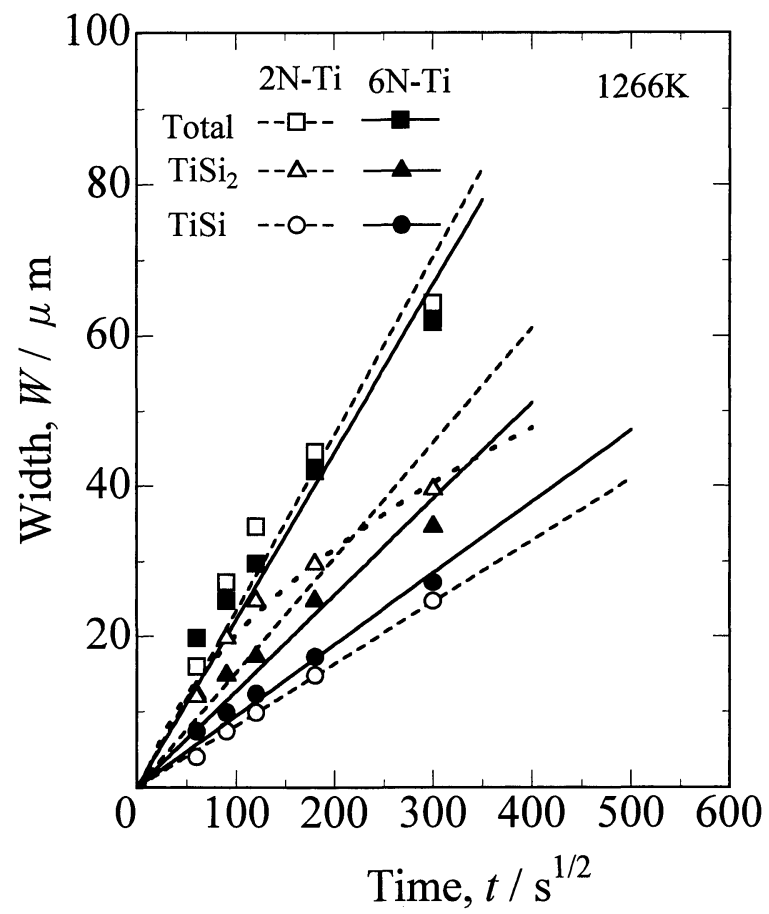

Fig. 3 Relationship between thickness, $W$, of $\mathrm{TiSi}_{2}$ and TiSi layers formed in the $2 \mathrm{~N}-\mathrm{Ti} / \mathrm{Si}$ and $6 \mathrm{~N}-\mathrm{Ti} / \mathrm{Si}$ diffusion couples and square root of annealing time at $1266 \mathrm{~K}$.

least square fitting under an intentional condition that the line start from the origin, $W=0$ at $t=0$. The other is determined by using only the data for the early stage of anneal. At $1323 \mathrm{~K}$, both $\mathrm{TiSi}_{2}$ and $\mathrm{TiSi}$ grow satisfying the parabolic law again as shown in Fig. 5.

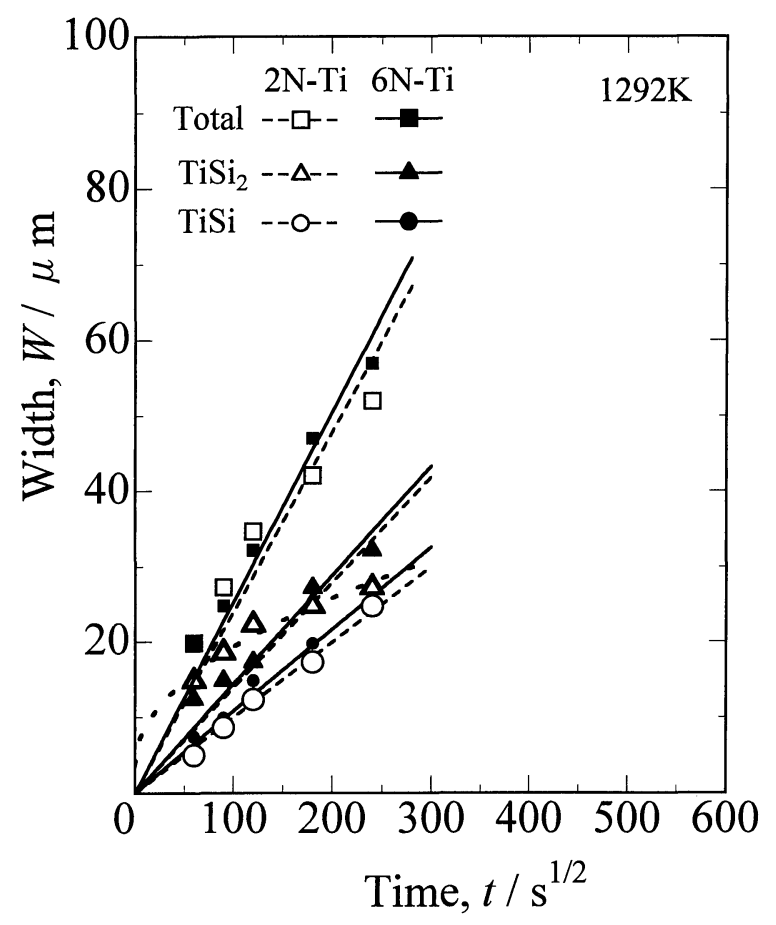

Fig. 4 Relationship between thickness, $W$, of $\mathrm{TiSi}_{2}$ and TiSi layers formed in the $2 \mathrm{~N}-\mathrm{Ti} / \mathrm{Si}$ and $6 \mathrm{~N}-\mathrm{Ti} / \mathrm{Si}$ diffusion couples and square root of annealing time at $1292 \mathrm{~K}$.

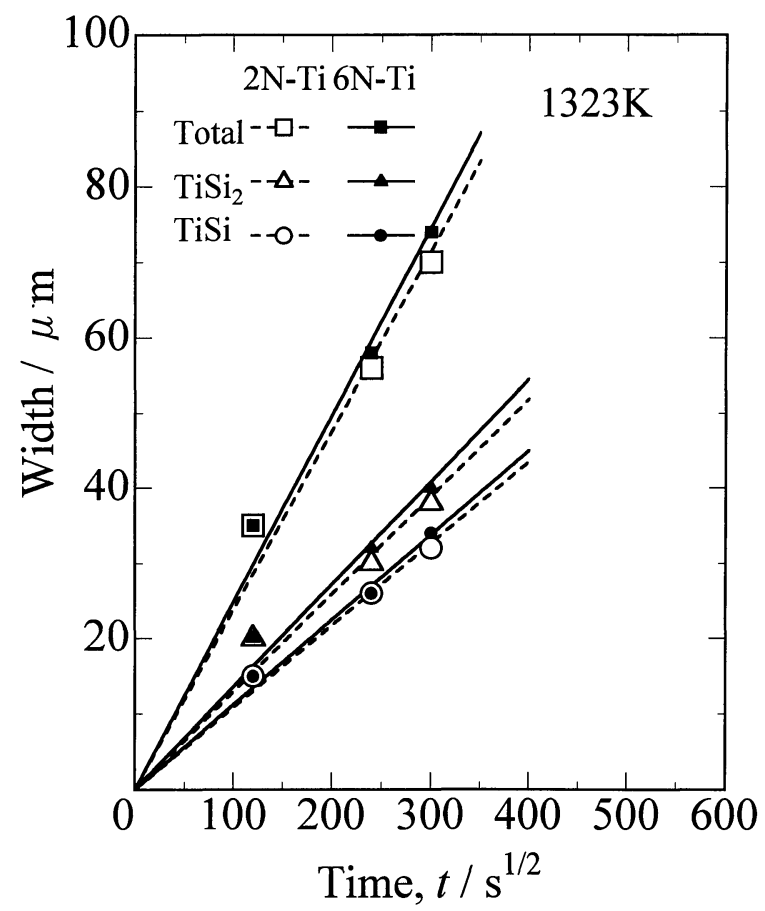

Fig. 5 Relationship between thickness, $W$, of $\mathrm{TiSi}_{2}$ and TiSi layers formed in the $2 \mathrm{~N}-\mathrm{Ti} / \mathrm{Si}$ and $6 \mathrm{~N}-\mathrm{Ti} / \mathrm{Si}$ diffusion couples and square root of annealing time at $1323 \mathrm{~K}$.

The Arrhenius plots of growth rate, $k^{2}$, of $\mathrm{TiSi}_{2}$ for both diffusion couples thus determined are shown in Fig. 6 together with our previous data ${ }^{(7)}$. The symbol, $\mathbf{0}$, for $2 \mathrm{~N}-\mathrm{Ti} / \mathrm{Si}$ couple at $973 \mathrm{~K}$ means that $\mathrm{TiSi}_{2}$ formed in this temperature has irregular morphology as has been 


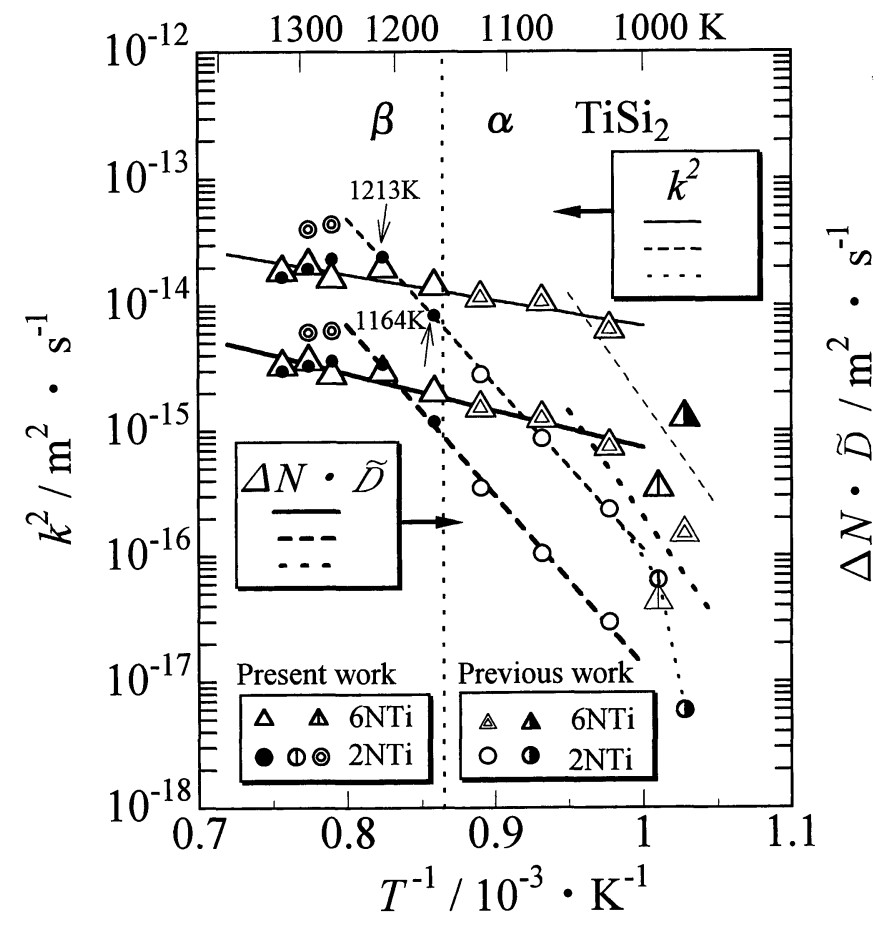

Fig. 6 Temperature dependence of the layer growth rate constant $k^{2}$ and $\Delta N \cdot \tilde{D}$ of $\mathrm{TiSi}_{2}$ for various types of diffusion couples.

reported previously ${ }^{(6)}$. The data at 1164 and $1213 \mathrm{~K}$ for $2 \mathrm{~N}-\mathrm{Ti} / \mathrm{Si}$ diffusion couple locate just on the extension of the linear broken line. The line is represented by

$$
k^{2}=1.8 \times 10^{-5} \exp \left(-251.5 \mathrm{~kJ} \cdot \mathrm{mol}^{-1} / \mathrm{RT}\right) \text {. }
$$

Although the data at 1266,1292 and $1323 \mathrm{~K}$ represented by symbol - deviate from the linear broken line, the Arrhenius plot is not affected by the transformation of Ti from the hcp to the bcc at $1156 \mathrm{~K}$. The data represented by symbol $(0)$ were those obtained by using only the data at the early stage of the anneal.

On the other hand, the Arrhenius plot of $k^{2}$ for $6 \mathrm{~N}$ $\mathrm{Ti} / \mathrm{Si}$ can be drawn by a linear line from 1023 to $1323 \mathrm{~K}$ while the datum at $973 \mathrm{~K}$ represented by symbol $\Delta$ deviates from the line. The linear line is approximated by

$$
k^{2}=7.9 \times 10^{-13} \exp \left(-39.4 \mathrm{~kJ} \cdot \mathrm{mol}^{-1} / \mathrm{RT}\right) \text {. }
$$

The activation energy, $39.4 \mathrm{~kJ} \cdot \mathrm{mol}^{-1}$, is very small in comparison with the values, $251.5 \mathrm{~kJ} \cdot \mathrm{mol}^{-1}$ for the $2 \mathrm{~N}$ $\mathrm{Ti} / \mathrm{Si}$ diffusion couple and $132 \mathrm{~kJ} \cdot \mathrm{mol}^{-1}$ reported in the previous paper ${ }^{(7)}$. In order to confirm the deviation of the symbol $\Delta$ from the line, a diffusion couple, $6 \mathrm{~N}$ $\mathrm{Ti} / \mathrm{Si} / 2 \mathrm{~N}-\mathrm{Ti}$, was annealed at $990 \mathrm{~K}$. The datum for the $6 \mathrm{~N}-\mathrm{Ti} / \mathrm{Si}$ diffusion couple is shown in Fig. 6 by the symbol, $\triangle$. It also deviates from the linear line, namely, a high activation energy is required in the lower temperature range. The symbol, $\Phi$, for $2 \mathrm{~N}-\mathrm{Ti} / \mathrm{Si}$ couple means that irregular morphology was observed in the $2 \mathrm{~N}-\mathrm{Ti} / \mathrm{Si}$ couple as was so at $973 \mathrm{~K}^{(6)}$. The authors have previously obtained such low activation energy in a high temperature range and high activation energy in a low temperature range in the reaction diffusion of $\mathrm{Ti}-\mathrm{Al}$ system ${ }^{(9)}$. The activation energy for growth of $\mathrm{TiAl}_{3}$ in the
$4 \mathrm{~N}-\mathrm{Ti} / \mathrm{Al}$ diffusion couple was $33.8 \mathrm{~kJ} \cdot \mathrm{mol}^{-1}$ and that in the $2 \mathrm{~N}-\mathrm{Ti} / \mathrm{Al}$ diffusion couple in the higher temperature range was $61.4 \mathrm{~kJ} \cdot \mathrm{mol}^{-1}$, while that in the lower temperature range was more than $250 \mathrm{~kJ} \cdot \mathrm{mol}^{-1}$. This phenomenon has been explained by correlating with the effects of diffusion barrier in the lower temperature range, i.e., diffusion of $\mathrm{Al}$ is controlled by the diffusion of $\mathrm{Al}$ in the diffusion barrier such as oxide film. The large activation energy in the low temperature range in the Ti-Si system can also be attributed to this diffusion barrier effect. The bend of the Arrhenius plot of $k^{2}$ of $\mathrm{TiSi}_{2}$ for the $2 \mathrm{~N}-\mathrm{Ti} / \mathrm{Si}$ diffusion couple above $1266 \mathrm{~K}$ will be explained by the effect of iron in the following.

\section{Temperature dependence of diffusion coefficients}

In general, Arrhenius plot of the value $k^{2}$ of a phase, $\alpha$, is not necessarily represented by a linear line because the value $k$ is influenced by the kind of adjacent phases, a drastic change of diffusion coefficient, for example, due to the phase transformation of the adjacent phase and the temperature dependence of solubility of the $\alpha$ phase or concentration gaps between the $\alpha$ phase and the adjacent phases ${ }^{(10)-(12)}$, while the plot of the interdiffusion coefficient, $\tilde{D}$, is represented by a linear line. Therefore, determination of interdiffusion coefficient has been tried. However, it is difficult because titanium silicides have very small solubility. So, here, $\Delta N \cdot \tilde{D}$ instead of $\tilde{D}$ has been determined with the aid of the Heumann's method $^{(13)}$ taking the effect due to the change in volume during diffusion anneal into account. Temperature dependence of $\Delta N \cdot \tilde{D}$ thus determined is shown in the Fig. 6 for $\mathrm{TiSi}_{2}$ and Fig. 7 for TiSi.

The values of $\Delta N \cdot \tilde{D}$ of $\mathrm{TiSi}_{2}$ are about $1 / 8$ of the values of $k^{2}$, so the plot of $\Delta N \cdot \tilde{D}$ is similar to that for $k^{2}$. The effect of the phase transformation of titanium at $1156 \mathrm{~K}$ on the value of $\Delta N \cdot \tilde{D}$ of $\mathrm{TiSi}_{2}$ is not observed on the Arrhenius plot. In this experiment, the diffusion layer of $\beta$ Ti phase could not be detected by EPMA analysis. So, the diffusion in the $\beta$ Ti phase seems to be very slow in comparison with that in $\mathrm{TiSi}_{2}$. Because the diffusion in the $\alpha$ Ti phase is also very slow, the transition from $\alpha$ to $\beta$ may affect nothing the growth of $\mathrm{TiSi}_{2}$, in other words, the diffusion layers of both $\alpha$ and $\beta$ phases are too narrow to influence the growth of $\mathrm{TiSi}_{2}$.

The pre-exponent factor and the activation energy are $6.8 \times 10^{-13}\left(\mathrm{~m}^{2} \cdot \mathrm{s}^{-1}\right)$ and $56.8\left(\mathrm{~kJ} \cdot \mathrm{mol}^{-1}\right)$ for $\mathrm{TiSi}_{2}$ in $6 \mathrm{~N}-\mathrm{Ti} / \mathrm{Si}$ diffusion couples in the temperature range from 1023 to $1323 \mathrm{~K}$ and $5.3 \times 10^{-4} \mathrm{~m}^{2} \cdot \mathrm{s}^{-1}$ and 260.3 $\mathrm{kJ} \cdot \mathrm{mol}^{-1}$ for $2 \mathrm{~N}-\mathrm{Ti} / \mathrm{Si}$ couples in the temperature range from 1023 to $1213 \mathrm{~K}$, respectively. The activation energy, $56.8 \mathrm{~kJ} \cdot \mathrm{mol}^{-1}$ for $\mathrm{TiSi}_{2}$ in $6 \mathrm{~N}-\mathrm{Ti} / \mathrm{Si}$ diffusion couples is very small.

The Arrhenius plots of $\Delta N \cdot \tilde{D}$ of TiSi for both type diffusion couples also show a deviation from the linear line at $1213 \mathrm{~K}$. Although the temperature dependence of $\Delta N$ can be considered as one of the possible reasons, there is no information about the temperature dependence of $\Delta N$.

The pre-exponent factor and the activation energy are 


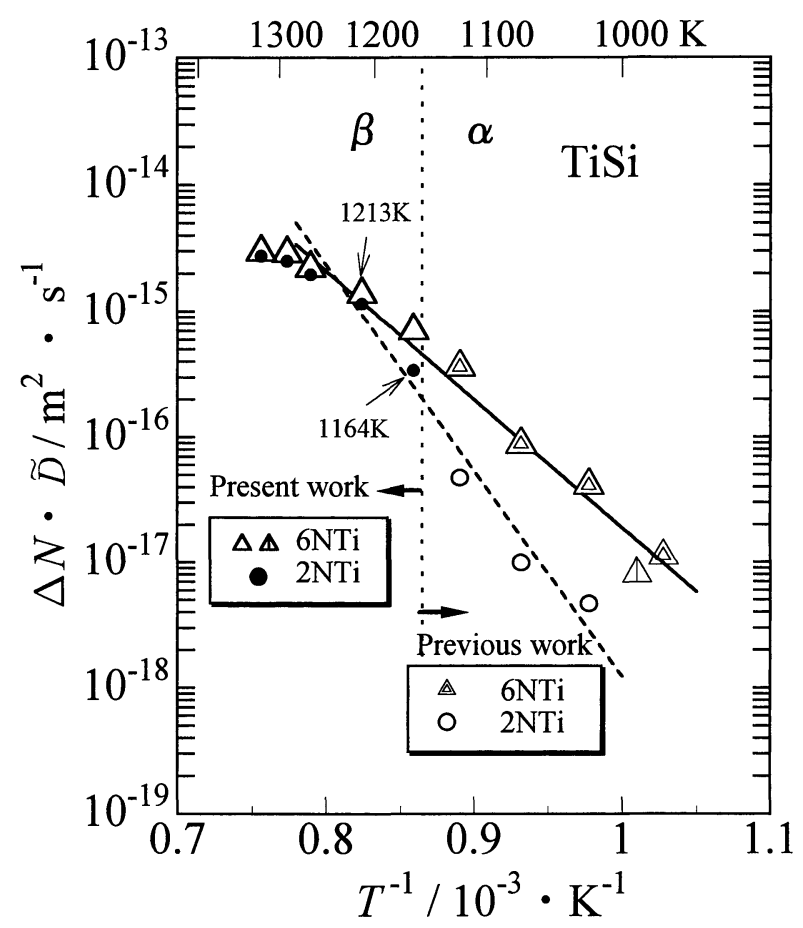

Fig. 7 Temperature dependence of the $\Delta N \cdot \tilde{D}$ of TiSi.

$3.4 \times 10^{-7}\left(\mathrm{~m}^{2} \cdot \mathrm{s}^{-1}\right)$ and $196.2\left(\mathrm{~kJ} \cdot \mathrm{mol}^{-1}\right)$ for $\mathrm{TiSi}_{2}$ in $6 \mathrm{~N}-\mathrm{Ti} / \mathrm{Si}$ diffusion couples in the temperature range between 973 and $1213 \mathrm{~K}$ and $3.3 \times 10^{-2} \mathrm{~m}^{2} \cdot \mathrm{s}^{-1}$ and 314.4 $\left(\mathrm{kJ} \cdot \mathrm{mol}^{-1}\right)$ for $2 \mathrm{~N}-\mathrm{Ti} / \mathrm{Si}$ couples in the temperature range between 1023 and $1213 \mathrm{~K}$. The values, $\Delta N \cdot \tilde{D}$, of TiSi formed in the $6 \mathrm{~N}-\mathrm{Ti} / \mathrm{Si}$ and $2 \mathrm{~N}-\mathrm{Ti} / \mathrm{Si}$ diffusion couples also become to have the same values in the high temperature range.

\section{Discussion}

The most interesting result obtained in this experiment is that the thicknesses of $\mathrm{TiSi}_{2}$ and TiSi formed in both $2 \mathrm{~N}-\mathrm{Ti} / \mathrm{Si}$ and $6 \mathrm{~N}-\mathrm{Ti} / \mathrm{Si}$ diffusion couples in the high temperature range become to have the same value. As reported previously, iron atoms segregate at grain boundaries in $2 \mathrm{~N}-\mathrm{Ti} / \mathrm{Si}$ diffusion couples (see Figs. 1(c), (d) in Ref. (6)) and they control the movement of almost of silicon and titanium atoms which pass through the boundaries. In addition, the $\mathrm{TiSi}_{2}$ layer has needle like columnar grains less than $1 \mu \mathrm{m}$ in diameter even in the diffusion couple annealed at the highest temperature in the previous experiment (e.g., see Fig. 2 in Ref. (6)) On the basis of these experimental results the grain boundary diffusion model has been proposed as a dominant diffusion process in Ti-Si system. This boundary diffusion model is also useful to explain the low activation energy in the $6 \mathrm{~N}-\mathrm{Ti} / \mathrm{Si}$ diffusion couples.

The present experimental result that the thickness of $\mathrm{TiSi}_{2}$ and TiSi formed in both $2 \mathrm{~N}-\mathrm{Ti} / \mathrm{Si}$ and $6 \mathrm{~N}-\mathrm{Ti} / \mathrm{Si}$ diffusion couples in the high temperature range become to have the same value can be explained by using this boundary diffusion model as follows. The iron atoms which segregate at grain boundary in the low temperature range redistribute into the matrix, i.e., TiSi and $\mathrm{TiSi}_{2}$ in the high temperature range then the effect of iron atoms vanishes.

In this experiment, $\mathrm{TiSi}_{2}$ layer has needle like columnar grains less than $3 \mu \mathrm{m}$ in diameter even at the highest temperature. This size is enough small so that we can consider the grain boundary diffusion model in this temperature range.

The authors have proposed some questions in the previous paper that "Does the boundary diffusion dominate the diffusion process in suh higher temperature range?" and "Can the phase growth follow the parabolic law under the condition that the boundary diffusion dominate the diffusion process while Bird ${ }^{(14)}$ and Lidiard et $a l .^{(15)}$ have pointed out a possibility of parabolic growth of diffusion layer in the reaction diffusion couple even though in a limited condition'". This experimental result supports the boundary diffusion model in such higher temperature range and the parabolic growth of diffusion layers even under the boundary diffusion dominated condition.

In this experiment, a non $t^{1 / 2}$ dependence has been observed for the growth of $\mathrm{TiSi}_{2}$ in $2 \mathrm{~N}-\mathrm{Ti} / \mathrm{Si}$ couple at 1266 and $1292 \mathrm{~K}$. Corcoran et al. ${ }^{(5)}$ have reported that the $\mathrm{TiSi}_{2}$ growth has a non $t^{1 / 2}$ dependence and is much better described by a grain boundary diffusion limited model. They studied the growth kinetics between deposited thin film $\mathrm{Ti}$ and $\langle 100\rangle$ or $\langle 111\rangle$ oriented $\mathrm{Si}$ wafers at $1023 \mathrm{~K}$ and the experiment was limited only for short times ranging from 5 to $45 \mathrm{~s}$ in a nitrogen ambient. In such early stage of annealing, the non $t^{1 / 2}$ dependence may be possible even though in the later stage of anneal, the growth becomes to satisfy the parabolic law.

Since, it has been suggested from our experimental results that the boundary diffusion dominates the diffusion process in the $\mathrm{Ti} / \mathrm{Si}$ system although the phase growth in $\mathrm{Ti} / \mathrm{Si}$ diffusion couples follows the parabolic law, so we should try to explain this non $t^{1 / 2}$ time dependence by an another way excepting the grain boundary limited growth model. As causes of a non $t^{1 / 2}$ time dependence growth of diffusion phase layer, some reasons can be considered. One is that due to the nonsimultaneous formation of diffusion phase layer as it has been well known in the reaction diffusion between silicon and metals as well as the $\mathrm{Fe}-\mathrm{Zn}$ binary system ${ }^{(16)}$. According to the previous study it has been shown ${ }^{(17)}$ that when a new phase is formed in a diffusion couple the growth of the new phase and the existing phase do not follow the parabolic law temporary. One is a breakdown of the experimental condition of semi-infinite solid during a long period isothermal anneal.

At least, both the non simultaneous formation of the diffusion phase layer and breakdown of the experimental condition of the semi-infinite solid for pure titanium and silicon could not be found at these temperatures. So, at present, the reason for the non $t^{1 / 2}$ time dependence growth of $\mathrm{TiSi}_{2}$ is not clear. One candidacy is a change of limiting process during the isothermal anneal which 
controls the growth of $\mathrm{TiSi}_{2}$ or TiSi. In the lower temperature range, width of the TiSi layer is very narrow, so $\mathrm{Fe}$ atoms can easily pass through $\mathrm{TiSi}$ and reach $\mathrm{TiSi}_{2}$. On the other hand, in the higher temperature range, the width of TiSi is relatively thick than that in the lower temperature range. So it needs a long time until $\mathrm{Fe}$ atoms reach $\mathrm{TiSi}_{2}$ layer. Until $\mathrm{Fe}$ atoms reach $\mathrm{TiSi}_{2}$ layer, the effect of $\mathrm{Fe}$ could not be detected. However, there are some questions. Why the width of $\mathrm{TiSi}_{2}$ at the early stage of anneal in the $2 \mathrm{~N}-\mathrm{Ti} / \mathrm{Si}$ couple can be thicker than that in the $6 \mathrm{~N}-\mathrm{Ti} / \mathrm{Si}$ couple at 1266 and $1292 \mathrm{~K}$. Are there some elements which enhance the diffusion in $\mathrm{TiSi}_{2}$ ? Further, why the activation energy for interdiffusion in $\mathrm{TiSi}_{2}$ formed in the $6 \mathrm{~N}-\mathrm{Ti} / \mathrm{Si}$ diffusion couple is so small?. To answer these questions, further experiment are required.

\section{Summary}

Reaction diffusion in the Ti-Si binary system has been studied by using sandwich-type bulk diffusion couples consisted of $99.5 \% \mathrm{Ti}, 99.9999 \% \mathrm{Ti}$ plates and $a\langle 111\rangle$ oriented $\mathrm{Si}$ wafer in the temperature range from 1164 to $1323 \mathrm{~K}$. The experimental results have been compared with our previous data obtained in the temperature range from 973 to $1123 \mathrm{~K}$. The results are summarized as follows.

(1) The growth rate of $\mathrm{TiSi}_{2}$ formed in $6 \mathrm{~N}-\mathrm{Ti} / \mathrm{Si}$ diffusion couples is faster than that in $2 \mathrm{~N}-\mathrm{Ti} / \mathrm{Si}$ couples at $1164 \mathrm{~K}$. However, they become to have the same values in the high temperature range. This means that the effect of iron on the growth of $\mathrm{TiSi}_{2}$ vanishes in the high temperature range.

(2) As one possible explanation for the result (1) it has been considered that in the higher temperature range, iron atoms which segregate at grain boundaries in the lower temperature range redistribute into the matrix, so the effect of iron at grain boundaries vanishes.

(3) The Arrhenius plots of the growth rate constant $k^{2}$ for $\mathrm{TiSi}_{2}$ and TiSi are not affected by the transition of Ti from $\alpha$ to $\beta$.

\section{Acknowledgments}

The authors would like to thank Sumitomo SiTiX Co. LTD and Mitsubishi Material Co. LTD for supply of the 99.9999\% titanium and silicon wafers, respectively. A part of this work was supported by the Grant-in-aid for scientific research on priority area (10136241) from the Ministry of Education, Science and Culture, Japan.

\section{REFERENCES}

(1) H. Kato and Y. Nakamura: Thin Solid Films, 34 (1976), 135.

(2) R. W. Bower and J. W. Mayer: Appl. Phys. Lett., 29 (1972), 359.

(3) W. K. Chu, S. S. Lau, J. W. Mayer and H. Muller and K. N. Tu: Thin Solid Films, 25 (1975), 393.

(4) S. P. Murarka and D. B. Fraser: J. Appl. Phys., 51 (1980), 342.

(5) Y. L. Corcoran, A. H. King, N. Laneroll and B. Kim: J. Elect. Mater, 19 (1990), 1177.

(6) T. Shimozaki, K. Chikumaru, Y. Wakamatsu and M. Onishi: J. Japan Inst. Metals, 60 (1996), 29.

(7) T. Shimozaki, T. Okino, M. Yamane, Y. Wakamatsu and M. Onishi: Trans. JIM, 38 (1997), 865.

(8) P. Nash and A. Nash: Binary Alloy Phase Diagrams, Vol. 2, ed. by T. B. Massalski et al., American Society for Metals, Metals Park, Ohio, (1986), p. 2056.

(9) T. Shimozaki, T. Okino, M. Yamane, Y. Wakamatsu and M. Onishi: Defect and Diffusion Forum, 143-147 (1997), 591.

(10) W. Seitz: Diffusion in Metallen, Springer Verlag, Berlin, (1955), 158.

(11) G. V. Kidson: J. Nucl. Mater., 3 (1961), 21

(12) S. Tuji: J. Japan Inst. Metals, 41 (1977), 678.

(13) Th. Heumann: Z. Phys. Chem., 201 (1952), 168.

(14) J. D. Baird: J. Nucl. Energy, Part A, 11 (1960), 81

(15) A. B. Lidiard and K. Tharmalingam: Disc. Faraday Soc., 28 (1959), 64.

(16) M. Onishi, Y. Wakamatsu and H. Miura: Trans. JIM., 15 (1974), 331.

(17) T. Shimozaki, Y. Wakamatsu and M. Onishi: J. Japan Inst. Metals, 57 (1993), 1376. 